\title{
Pengaruh Sponsorship terhadap Brand Awareness Livin' by Mandiri (Studi pada Event E-Sport MPL ID Season 8)
}

\author{
Andy Gunawan', H. H. Daniel Tamburian ${ }^{2 *}$ \\ ${ }^{1}$ Fakultas Ilmu Komunikasi, Universitas Tarumanagara, Jakarta \\ Email: andy.915180082@stu.untar.ac.id \\ ${ }^{2}$ Fakultas Ilmu Komunikasi, Universitas Tarumanagara, Jakarta* \\ Email:danielt@fikom.untar.ac.id
}

Masuk tanggal : 15-12-2021, revisi tanggal : 06-01-2022, diterima untuk diterbitkan tanggal : 16-01-2022

\begin{abstract}
Sponsorship is a type of marketing or advertising that, when done correctly, can be very effective. Livin' by Mandiri, a mobile banking product that is accessible and has a target market of young people who need practicality, is one of Bank Mandiri's newest products. The purpose of this study was to know if sponsorship at the MPL ID Season 8 event influenced Livin' by Mandiri's brand awareness. Sponsorship and Brand Awareness are the variables used in this study. In this study, sponsorship has three dimensions: target audience reach, compatibility with the company's or brand's positioning, and message capacity. In this study, brand awareness has four dimensions: Unaware of Brand, Brand Recognition, Brand Recall, and Top of Mind. This study used quantitative research methods, and the population studied in this research is the MPL ID Season 8 audience, which has an average viewership 447,142 viewers. The Slovin formula was used to find the number of samples needed in this research. The data in this study indicates that sponsorship at the MPL ID Season 8 event has an effect on Livin' by Mandiri brand awareness, there is a sufficient connection between sponsorship and brand awareness, and there is a strong influence between sponsorship and brand awareness.
\end{abstract}

Keywords: brand awareness, e-sport, sponsorship

\begin{abstract}
Abstrak
Sponsorship merupakan salah satu cara pemasaran atau periklanan yang sangat efektif jika dilakukan dengan tepat. Salah satu produk terbaru dari Bank Mandiri adalah Livin’ by Mandiri, produk mobile banking yang dapat diakses dan mempunyai target pasar anak-anak muda yang membutuhkan kepraktisan. Tujuan penelitian ini adalah untuk mengetahui apakah sponsorship pada event MPL ID Season 8 berpengaruh terhadap brand awareness Livin' by Mandiri. Variabel pada penelitian ini adalah Sponsorship dan Brand awareness. dimensi sponsorship adalah Target Audience Reach, Compatibility with the Company's or Brand's Positioning \& Message Capacity. Dimensi brand awareness yaitu Unaware of Brand, Brand Recognition, Brand Recall, Top of Mind. Peneliti menggunakan metode penelitian kuantitatif dan populasi penelitian ini adalah penonton MPL ID Season 8 yang mempunyai average viewers sebanyak 447,142 penonton. Untuk menentukan jumlah sampel yang dibutuhkan, peneliti menggunakan rumus Slovin. Hasil data pada penelitian ini menunjukkan bahwa terdapat pengaruh dari sponsorship pada event MPL ID Season 8 terhadap brand awareness Livin' by Mandiri. Dari data penelitian ini, ditemukan bahwa terdapat hubungan yang cukup antara sponsorship dan brand awareness, dan terdapat pengaruh yang signifikan antara sponsorship dan brand awareness.
\end{abstract}

Kata Kunci: e-sport, kesadaran merek, sponsorship 


\section{Pendahuluan}

Tidak dapat dibantah lagi bahwa game online merupakan salah satu trend yang sedang marak-maraknya. Pandemi global Covid-19 juga mempengaruhi kenaikan pemain dan peminat game online, melansir Inews.id APJII memaparkan bahwa aktivitas penghibur yang dilakukan selama pandemi Covid-19 oleh masyarakat Indonesia adalah bermain game online dengan persentase sebesar $16,5 \%$. Melihat data tersebut pasti akan membuat perusahaan-perusahaan tertarik untuk berpartisipasi dalam industri game online dengan berbagai cara (Dahwilani, 2020).

Salah satu mobile game yang digemari oleh masyarakat Indonesia adalah Mobile Legends : Bang Bang. Game MOBA 5 (lima) vs 5 (lima) ini adalah mobile game terpopuler di Indonesia pada tahun 2021 menurut App Annie melansir dari infokomputer.grid.id (Rizal, 2021). Memiliki popularitas yang begitu tinggi, Mobile Legends mempunyai skena profesional yang diminati oleh banyak orang. Salah satu acara yang paling ramai penonton pada skena profesional game tersebut adalah MPL (Mobile Legends Bang Bang Professional League).

MPL (Mobile Legends Bang Bang Professional League) adalah acara liga kasta tertinggi yang dibuat langsung oleh developer Mobile Legends yaitu Moonton. Acara ini ada di beberapa negara Asia Tenggara dan salah satu negara diluar Asia Tenggara adalah Brazil. Sudah 8 Musim MPL hadir di Indonesia dan banyak torehan yang dihasilkan oleh MPL, salah satunya adalah acara $e$-sport yang paling digemari di Asia Tenggara pada tahun 2020, sehingga MPL merupakan salah satu acara yang menarik untuk perusahaan-perusahaan yang ingin memperkuat merek mereka dengan menjadi sponsor dari acara tersebut. Salah satu sponsor tersebut adalah Bank Mandiri

Bank Mandiri adalah bank BUMN yang mempunyai beberapa produk, salah satunya adalah Livin 'by Mandiri. Livin' by Mandiri adalah layanan internet dan mobile banking dari Bank Mandiri yang menargetkan anak-anak muda sebagai pengguna atau konsumennya. Menjadi Official Bank Partner MPL ID sebagai bentuk sponsor, Livin' by Mandiri dapat menggapai target pasar yang tepat yaitu anak-anak muda yang membutuhkan layanan internet/ mobile banking. Sponsor ini banyak memberikan promo dan keuntungan untuk para penonton MPL, contohnya memberikan Diamond (alat tukar atau mata uang di game Mobile Legends) untuk pembukaan rekening menggunakan kode khusus, dll. Menjalin sponsorship dengan salah satu acara terbesar di Indonesia, Livin' by Mandiri pasti berharap dapat mempengaruhi kesadaran merek (brand awareness) pada pikiran para penonton MPL Indonesia.).

\section{Metode Penelitian}

Penelitian ini berjudul Pengaruh Sponsorship Terhadap Brand awareness Livin' by Mandiri (Studi pada Event MPL ID Season 8), dan pertanyaan pada penelitian ini adalah "Bagaimana pengaruh sponsorship yang dilakukan oleh Livin' by Mandiri pada MPL ID Season 8 terhadap kesadaran merek (brand awareness) Livin' by Mandiri?", maka pendekatan penelitian ini adalah pendekatan kuantitatif.

Metode penelitian pada dasarnya merupakan cara ilmiah untuk mendapatkan data dengan tujuan dan kegunaan tertentu. Karena penelitian ini menggunakan pendekatan kuantitatif dan memerlukan data yang diperoleh dari jawaban responden melalui kuisioner, maka metode penelitian ini adalah metode survei. 
Populasi yang akan diteliti adalah penonton MPL ID Season delapan yang mempunyai average viewers 447,142 orang. Menurut Sugiyono (2013) Metode sampling yang harus digunakan adalah probability sampling yang merupakan metode sampling yang memberikan peluang yang tidak berbeda bagi semua populasi untuk menjadi anggota sampel dan menggunakan teknik simple random sampling karena pengambilan anggota sampel dari populasi dilakukan secara acak tanpa memperdulikan status sosial atau tingkatan masyarakat. Dengan melakukan penghitungan memakai rumus Slovin, peneliti mendapati bahwa pada penelitian ini jumlah sampel yang diperlukan adalah 100 sampel. Data pada penelitian ini adalah data primer dan data sekunder. Data primer berasal dari jawaban kuesioner yang akan disebarkan online dalam bentuk Google Form. Data sekunder berasal dari dokumentasi dan studi kepustakaan yang meliputi buku, jurnal, laporan yang dipublikasikan, skripsi, dan website.

\section{Hasil Temuan dan Diskusi}

Karakterisitik responden berdasarkan penonton MPL ID Season 8 terdiri dari dua jenis, yaitu penonton dan bukan penonton. Hasil analisis data responden berdasarkan penonton MPL ID Season 8 adalah semua responden pada penelitian ini adalah penonton MPL ID Season 8.

Karakteristik responden berdasarkan mengetahui Livin' by Mandiri terbagi menjadi dua, yaitu mengetahui dan tidak mengetahui. Hasil analisis data responden berdasarkan mengetahui Livin' by Mandiri adalah sebanyak 98 responden atau 98\% dari total responden mengetahui Livin' by Mandiri dan 2 responden atau 2\% dari dari total responden tidak mengetahui Livin' by Mandiri.

Tabel 1. Hasil Uji Validitas

\begin{tabular}{|c|c|c|c|c|}
\hline Variabel & Pertanyaan Indikator & $\begin{array}{c}\text { Pearson } \\
\text { Correlation }\end{array}$ & $\begin{array}{l}\text { Sig }(2- \\
\text { tailed) }\end{array}$ & Ket. \\
\hline \multirow{4}{*}{$\begin{array}{l}\text { Sponsorship } \\
\text { (X) }\end{array}$} & $\begin{array}{l}\text { Sponsorship Livin' by Mandiri pada } \\
\text { MPL ID Season } 8 \text { menjangkau } \\
\text { audiens yang tepat }\end{array}$ & 0.844 & 0.00 & Valid \\
\hline & $\begin{array}{l}\text { Sponsorship Livin' by Mandiri pada } \\
\text { MPL ID Season } 8 \text { menarik perhatian }\end{array}$ & 0.833 & 0.00 & Valid \\
\hline & $\begin{array}{c}\text { Produk Livin' by Mandiri berkaitan } \\
\text { dengan MPL ID Season } 8\end{array}$ & 0.838 & 0.00 & Valid \\
\hline & $\begin{array}{l}\text { Mengerti pesan dari sponsorship } \\
\text { pada MPL ID Season } 8 \text { yang } \\
\text { dilakukan oleh Livin' by Mandiri }\end{array}$ & 0.860 & 0.00 & Valid \\
\hline \multirow{3}{*}{$\begin{array}{l}\text { Brand } \\
\text { awareness } \\
\quad(\mathrm{Y})\end{array}$} & $\begin{array}{l}\text { Tidak mengetahui merek Livin' by } \\
\text { Mandiri setelah menonton MPL ID } \\
\text { Season } 8\end{array}$ & 0.607 & 0.00 & Valid \\
\hline & $\begin{array}{l}\text { Mengetahui merek Livin' by Mandiri } \\
\text { setelah menonton MPL ID Season } 8\end{array}$ & 0.654 & 0.00 & Valid \\
\hline & $\begin{array}{l}\text { Mengetahui dan beberapa kali } \\
\text { menyebut atau mengingat kembali } \\
\text { merek Livin' by Mandiri setelah } \\
\text { menonton MPL ID Season } 8\end{array}$ & 0.723 & 0.00 & Valid \\
\hline
\end{tabular}


Mengingat Livin' by Mandiri saat

pertama kali kata bank atau

perbankan disebutkan setelah

menonton MPL ID Season 8

Sumber: Olahan Peneliti dengan SPSS

Tabel 2. Hasil Uji Realibilitas

\begin{tabular}{cccc}
\hline No & Variabel & Cronbach's Alpha & Keterangan \\
\hline 1 & Sponsorship $(\mathrm{X})$ & 0.861 & Realibel \\
2 & Brand awareness $(\mathrm{Y})$ & 0.600 & Realibel \\
\hline
\end{tabular}

Sumber: Olahan Peneliti dengan SPSS

Tabel 3. Hasil Uji Analisis Regresi Sederhana

\begin{tabular}{llccccc}
\hline & & & & & \\
& Model & B & Std. Error & Beta & t & Sig. \\
\hline \multirow{2}{*}{1} & (Constant) & 4.595 & 1.125 & & 4.085 & .000 \\
& Sponsorship & .577 & .081 & .586 & 7.159 & .000 \\
\hline
\end{tabular}

Sumber: Olahan Peneliti dengan SPSS

Variabel penelitian ini adalah Sponsorship (X) dan Brand awareness (Y). Tujuan yang ingin peneliti capai pada penelitian ini adalah mengetahui hubungan dan pengaruh dari variabel tersebut. Uji yang dilakukan dalam membuktikan hubungan antara variabel tersebut adalah melakukan uji koefisien korelasi. Hasil penelitian adalah kedua variabel dapat dinyatakan memiliki hubungan apabila nilai korelasi berada diantara $-1 \leq 0 \leq 1$.

Dari melakukan uji koefisien korelasi, peneliti juga dapat mengetahui tingkat dari hubungan antara kedua variabel tersebut. Tingkat hubungan dapat ditentukan dari seberapa besar nilai korelasi yang dimiliki oleh kedua variabel. Pada penelitian ini peneliti mendapatkan nilai korelasi 0.586, yang dimana dapat disimpulkan bahwa kekuatan hubungan antara variabel Sponsorship pada event MPL ID Season 8 dengan variabel Brand awareness Livin' by Mandiri berada pada tingkat hubungan yang cukup.

Untuk membuktikan pengaruh sponsorship kepada brand awareness Livin' by Mandiri, peneliti menggunakan uji analisis regresi sederhana. Pada uji analisis regresi sederhana, ditemukan nilai konstanta sebesar 4.595 sedangkan nilai kredibilitas sebesar 0.577. Kedua nilai tersebut dapat disimpulkan menjadi $\mathrm{Y}=4.595+0.577 \mathrm{X}$. Nilai konstanta dan koefisien regresi mendapatkan nilai positif, sehingga dapat diartikan semakin meningkat sponsorship Livin' by Mandiri maka Brand awareness Livin' by Mandiri akan semakin meningkat juga.

Dalam membuktikan besar pengaruh dari variabel $\mathrm{X}$ terhadap variabel $\mathrm{Y}$, dilakukan uji parsial (T). Pada uji tersebut, peneliti menemukan hasil nilai signifikansi pada penelitian ini adalah 0.00. Apabila nilai signifikansi adalah $0.00<0.05$, maka disimpulkan bahwa variabel X memberikan pengaruh signifikan terhadap variabel Y. Maka dapat disimpulkan bahwa sponsorship pada event MPL ID Season 8 memberikan pengaruh signifikan terhadap brand awareness Livin' by Mandiri.

Dari hasil kedua uji yang peneliti lakukan, yaitu uji analisis regresi sederhana dan uji T, dapat peneliti simpulkan bahwa hipotesis dalam penelitian ini menghasilkan Ho ditolak dan Ha diterima. Hipotesis Ha yang diterima tersebut adalah ada pengaruh antara sponsorship terhadap brand awareness Livin' by Mandiri. 
Andy Gunawan, H. H. Daniel Tamburian: Pengaruh Sponsorship terhadap Brand Awareness Livin' by Mandiri (Studi pada Event E-Sport MPL ID Season 8)

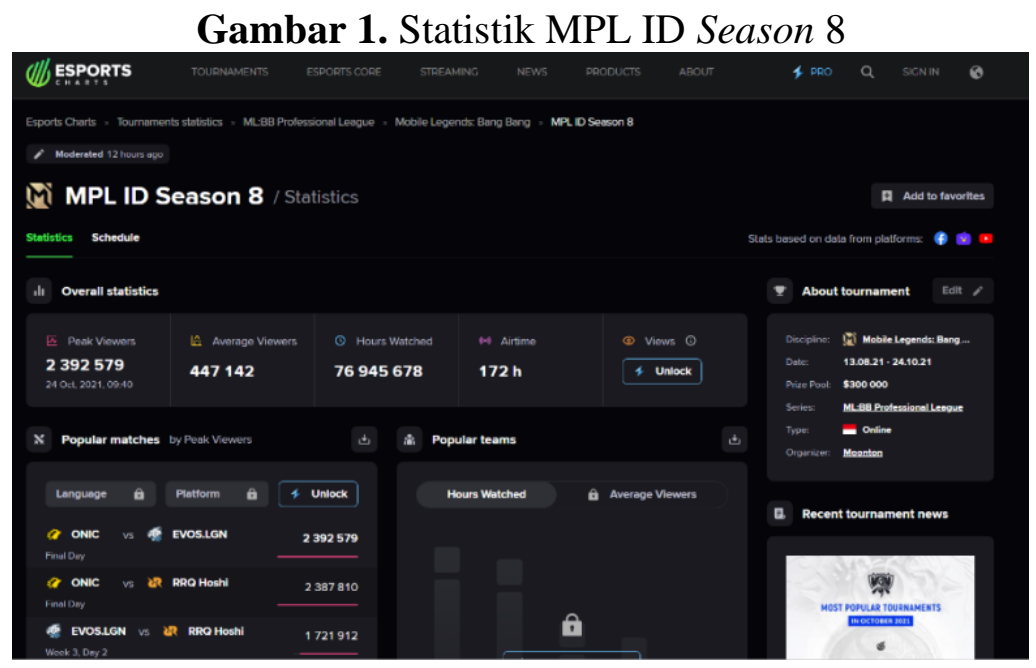

Sumber: Esports Charts

\section{Simpulan}

Penelitian ini memiliki dua variabel, yaitu sponsorship (X) dan brand awareness (Y). untuk membuktikan adanya hubungan antara kedua variabel tersebut adalah menggunakan uji koefisien korelasi. Hasil penelitian adalah kedua variabel dapat dinyatakan memiliki hubungan dikarenakan nilai korelasi pada penelitian ini adalah 0,586. Dipaparkan bahwa apabila nilai korelasi berada diantara $-1 \leq 0 \leq 1$, maka terdapat hubungan antara kedua variabel. Melalui uji koefisien korelasi, peneliti juga dapat mengetahui tingkat dari hubungan antara kedua variabel tersebut.

Tingkat hubungan dapat ditentukan dari seberapa besar nilai korelasi yang dimiliki oleh kedua variabel. Pada penelitian ini peneliti mendapatkan nilai korelasi 0.586, melihat pada tabel 3.2 yang dimana dapat penulis simpulkan bahwa kekuatan hubungan antara variabel Sponsorship pada event MPL ID Season 8 dengan variabel brand awareness Livin' by Mandiri berada pada tingkat hubungan yang cukup karena berada di 0,400 - 0,599. Untuk membuktikan adanya pengaruh sponsorship terhadap brand awareness Livin' by Mandiri, peneliti menggunakan uji analisis regresi sederhana. Pada uji analisis regresi sederhana, peneliti menemukan nilai konstanta sebesar 4,595 sedangkan nilai kredibilitas sebesar 0,577. Kedua nilai tersebut dapat disimpulkan menjadi $\mathrm{Y}=4.595+0.577 \mathrm{X}$. Nilai konstanta dan koefisien regresi mendapatkan nilai positif, sehingga dapat diartikan semakin meningkat sponsorship Livin' by Mandiri maka brand awareness Livin' by Mandiri akan semakin meningkat juga. Dalam membuktikan seberapa signifikan pengaruh dari variabel independen terhadap variabel dependen, peneliti menggunakan uji parsial (uji T).

Pada uji tersebut, peneliti menemukan hasil nilai signifikan pada penelitian ini adalah 0.00. Melihat dari pernyataan untuk uji T di atas. Menurut Ghozali (2018:179) Apabila nilai signifikansi adalah $0.00<0.05$, maka dinyatakan bahwa variabel independen memberikan pengaruh signifikan terhadap variabel dependen. Sehingga dapat disimpulkan bahwa sponsorship pada event MPL ID Season 8 memberikan pengaruh signifikan terhadap brand awareness Livin' by Mandiri pada penelitian ini. Dari hasil kedua uji yang peneliti lakukan, yaitu uji analisis regresi sederhana dan uji $\mathrm{T}$, dapat peneliti simpulkan bahwa hipotesis dalam penelitian ini menghasilkan Ho ditolak dan Ha diterima. Hipotesis Ha yang diterima tersebut adalah ada pengaruh antara sponsorship terhadap brand awareness Livin' by Mandiri. 


\section{Ucapan Terima Kasih}

Peneliti ingin mengucapkan terima kasih kepada Fakultas Ilmu Komunikasi Universitas Tarumanagara, narasumber, serta semua pihak yang turut membantu peneliti sehingga penelitian ini dapat diselesaikan.

\section{Daftar Pustaka}

Dahwilani, D. M. (2020, December 23). Survei: 16,5 Persen Masyarakat Habiskan Waktu Main Game Online selama Pandemi Covid-19. INews.ID. Diakses pada 15 Agustus 2021 dari https://www.inews.id/techno/internet/survei-165-persenmasyarakat-habiskan-waktu-main-game-online-selama-pandemi-covid-19

MPL ID Season 8 Statistics. (2021, October 25). Esports Charts. Diakses pada 5 November 2021 dari https://escharts.com/tournaments/mobile-legends/mpl-idSeason-8

Rizal, A. (2021, August 16). Mobile Legends Jadi Mobile Game Paling Favorit di Indonesia 2021 - Info Komputer. Info Komputer; grid.id. Diakses pada 18 Agustus 2021 dari https://infokomputer.grid.id/read/122840670/mobilelegends-jadi-mobile-game-paling-favorit-di-indonesia-2021

Salma, A. N. (2017). PENGARUH SPONSORSHIP DALAM MENINGKATKAN BRAND AWARENESS (Studi pada Sponsorship Garuda Indonesia Terhadap Liverpool FC sebagai Global Official Airline Partner). Interdisciplinary Journal of Communication, Vol 2, No.1.

Sugiyono. 2013. Metode Penelitian Pendidikan Pendekatan Kuantitatif, Kualitatif, dan $R \& D$. Bandung: Alfabeta. 